\title{
Successful treatment of a gastric leak after bariatric surgery using endoluminal vacuum therapy
}

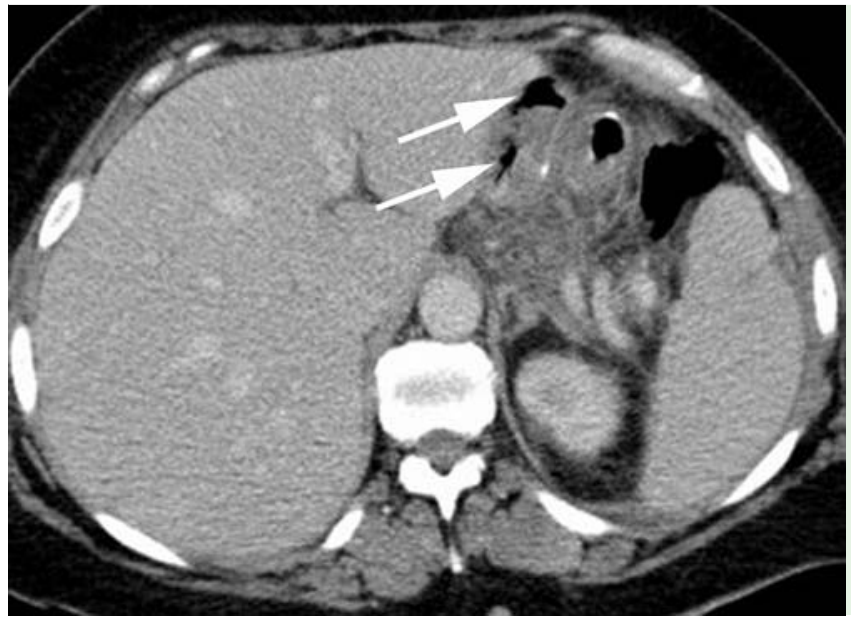

Fig. 1 Computer tomography (CT) scan in a morbidly obese woman with a leak from the gastric pouch following a Roux-en-Y gastric bypass showing paragastric air and fluid collections (arrows).

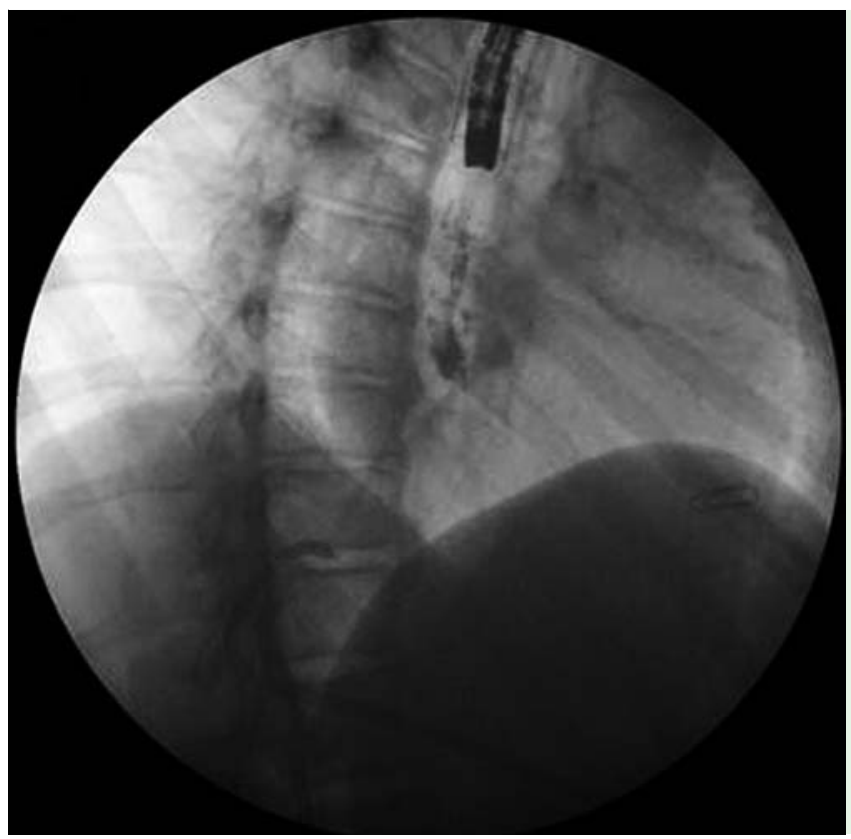

A gastric leak after bariatric surgery is a serious complication [1]. Its successful management requires considerable experience, expertise, and a patient-tailored, multidisciplinary therapeutic approach [1]. The effectiveness of surgical re-intervention is limited by the compromised and inflamed tissue adjacent to the leak, which makes its adequate closure either difficult or impossible $[1,2]$. In contrast, available endoscopic interventions, including fibrin sealing [2], over-the-scope clipping [3], and the insertion of intraluminal covered stents [1], have been shown to be good treatment options. Preliminary experience with endoluminal vacuum therapy has provided supportive evidence for the efficacy of this intervention in the management of leaks following gastroesophageal anastomoses [4,5]. The favorable effects of this treatment may be due to the reduction in the intraluminal pressure and the marked growth of granulation tissue that it induces.

A 41-year-old morbidly obese woman who had undergone RouX-en-Y gastric bypass (RYGB) developed a major gastric leak ( Fig. 1 and Fig.2). Previously, two attempts had been made to seal the leak using covered metal stents $(24 \mathrm{~mm} \times$ $10 \mathrm{~cm}$; Beta-stent $26 / 34 \mathrm{~mm} \times 12 \mathrm{~cm}$; both Taewoong Medical), but in both cases

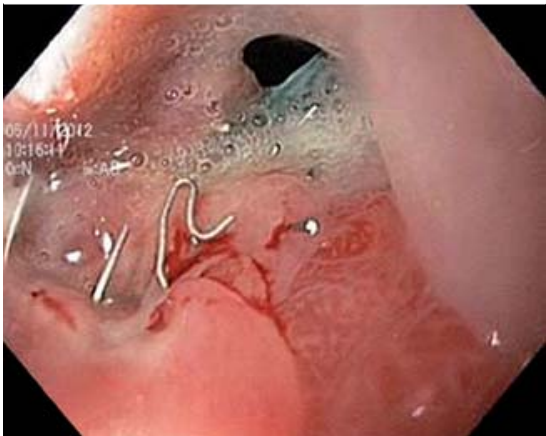

Fig. 2 Endoscopic view showing the leak before insertion of the sponge.
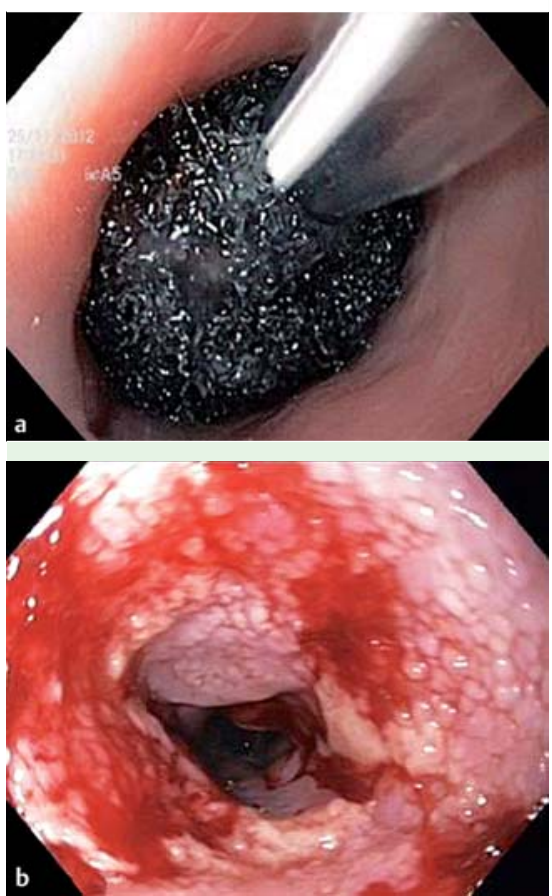

Fig.4 Endoscopic views showing: a insertion of the polyurethane sponge; $\mathbf{b}$ the appearance after 6 days of endoluminal vacuum therapy.

the stents had migrated distally. We decided to endoscopically position a polyurethane sponge in the wound cavity ( Fig. 3 and $\bullet$ Fig.4a). Continuous suction $(125 \mathrm{mmHg})$ was applied via drainage tubes fixed to the sponge, which was changed every third day. Adequate closure of the leak was achieved within 1 week ( Fig.4b). Endoscopic and radiological investigations performed 6 months following discharge confirmed the leak had sealed completely, without signs of stenosis. 
Therefore, we consider endoscopic vacuum therapy to be a promising choice for the treatment of complicated major leaks from the gastric pouch after RYGB. There is a need for technical improvements in the currently available vacuum therapy systems in order to make them more effective after complicated bariatric surgery.

Endoscopy_UCTN_Code_TTT_1AO_2AI

Competing interests: None

F. Seyfried ${ }^{1,2}$, S. Reimer ${ }^{3}$, A. D. Miras' ${ }^{2}$, W. Kenn ${ }^{4}$, C.-T. Germer ${ }^{1}$, M. Scheurlen ${ }^{3}$, C. Jurowich ${ }^{1}$

${ }^{1}$ Department of General, Visceral, Vascular and Pediatric Surgery, University Hospital of Würzburg, Würzburg, Germany

${ }^{2}$ Imperial Weight Centre, Department of Investigative Medicine, Imperial

College London, UK
${ }^{3}$ Medizinische Klinik und Poliklinik II, Department of Gastroenterology, University of Würzburg, Würzburg, Germany ${ }^{4}$ Department of Radiology, University of Würzburg, Würzburg, Germany

\section{References}

1 Spyropoulos C, Argentou MI, Petsas T et al. Management of gastrointestinal leaks after surgery for clinically severe obesity. Surg Obes Relat Dis 2012; 8: 609-615

2 Papavramidis ST, Eleftheriadis EE, Papavramidis TS et al. Endoscopic management of gastrocutaneous fistula after bariatric surgery by using a fibrin sealant. Gastrointest Endosc 2004; 59: 296-300

3 Conio M, Blanchi S, Repici A et al. Use of an over-the-scope clip for endoscopic sealing of a gastric fistula after sleeve gastrectomy. Endoscopy 2010; 42 (Suppl. 02): E71 -E72

4 Ahrens M, Schulte T, Egberts J et al. Drainage of esophageal leakage using endoscopic vacuum therapy: a prospective pilot study. Endoscopy 2010; 42: 693-698

5 Loske G, Schorsch T, Muller C. Intraluminal and intracavitary vacuum therapy for esophageal leakage: a new endoscopic minimally invasive approach. Endoscopy 2011; 43: $540-544$
Bibliography

Dol http://dx.doi.org/

10.1055/s-0033-1344569

Endoscopy 2013; 45: E267-E268

(c) Georg Thieme Verlag KG

Stuttgart · New York

ISSN 0013-726X

\section{Corresponding author}

\section{F. Seyfried, MD}

Department of General, Visceral, Vascular and Pediatric Surgery

University Hospital of Würzburg

Oberdürrbacher Straße 6

97080 Würzburg

Germany

Fax: +49-931-20131009

Seyfried_f@chirurgie.uni-wuerzburg.de 